\title{
Measurements and Simulations on the Mechanisms of Efficiency Losses in HIT Solar Cells
}

\author{
Silvio Pierro, ${ }^{1}$ Andrea Scuto, ${ }^{2}$ Luca Valenti, ${ }^{2}$ Marina Foti, ${ }^{3}$ Anna Battaglia, ${ }^{4}$ \\ Giovanni Mannino, ${ }^{2}$ Cosimo Gerardi, ${ }^{3}$ Felice Crupi, ${ }^{1}$ and Salvatore Lombardo ${ }^{2}$ \\ ${ }^{1}$ DIMES, Università della Calabria, Via P. Bucci, 87036 Rende, Italy \\ ${ }^{2}$ CNR-IMM, Strada VIII 5, 95121 Catania, Italy \\ ${ }^{3}$ STMicroelectronics, Stradale Primosole 50, 95121 Catania, Italy \\ ${ }^{4} 3$ SUN S.r.l., Contrada Blocco Torrazze, sn, 95121 Catania, Italy \\ Correspondence should be addressed to Silvio Pierro; pierro@dimes.unical.it
}

Received 1 October 2014; Revised 17 February 2015; Accepted 18 February 2015

Academic Editor: Olindo Isabella

Copyright (C) 2015 Silvio Pierro et al. This is an open access article distributed under the Creative Commons Attribution License, which permits unrestricted use, distribution, and reproduction in any medium, provided the original work is properly cited.

\begin{abstract}
We study the electrical and the optical behavior of HIT solar cell by means of measurements and optoelectrical simulations by TCAD simulations. We compare the HIT solar cell with a conventional crystalline silicon solar cell to identify the strengths and weaknesses of the HIT technology. Results highlight different mechanisms of electrical and optical efficiency losses caused by the presence of the amorphous silicon layer. The higher resistivity of the a-Si layers implies a smaller distance between the metal lines that causes a higher shadowing. The worst optical coupling between the amorphous silicon and the antireflective coating implies a slight increase of reflectivity around the $600 \mathrm{~nm}$ wavelength.
\end{abstract}

\section{Introduction}

The heterostructure with intrinsic thin layer solar cell, so called HIT, is the most promising monocrystalline silicon based technology to enhance the cost/efficiency factor [1]. This assumption is based on the enhancement made by the HIT with respect to a monocrystalline solar cell by the cost reduction introduced by the lower thermal budget, and by the increasing of the open circuit voltage thanks to the heterojunction barrier that decreases the minority current [2]. From the previous considerations we expect a strong increase in the HIT performance with respect to the $\mathrm{c}-\mathrm{Si}$ technology. The base research-cell efficiencies reported in literature tell us that the efficiency of the HIT solar cell is slightly higher than the efficiency of the microcrystalline bulk solar cell ( $25.6 \%$ of HIT against $25 \%$ of bulk microcrystalline) [3]. Subsequent improvements have allowed HIT solar cells to reach the efficiency of $25.6 \%$ [4]. Actually, the main focus to increase the HIT efficiency is connected to the surface recombination velocity at amorphous-crystalline interface [5]. In order to further increase the cell efficiency we need to understand the main causes of efficiency losses and how to reduce them.

This paper focuses the attention on the physical aspects that affect the HIT solar cells different from technological aspects as surface passivation or defect densities. For this purpose we compare measurements of bulk crystalline silicon solar cell with the equivalent HIT solar cell. Furthermore, by using a commercial TCAD simulator [6] tuned with device measurements, we intend to investigate the main loss mechanisms for both structures and identify the main problems of the HIT technology.

The remainder of this paper is organized as follows. Section 2 describes the process details of the realized samples and the simulation setup. Section 3 reports the experimental and numerical results and discusses the main phenomena affecting the HIT efficiency. Section 4 reports the conclusions of this work. 

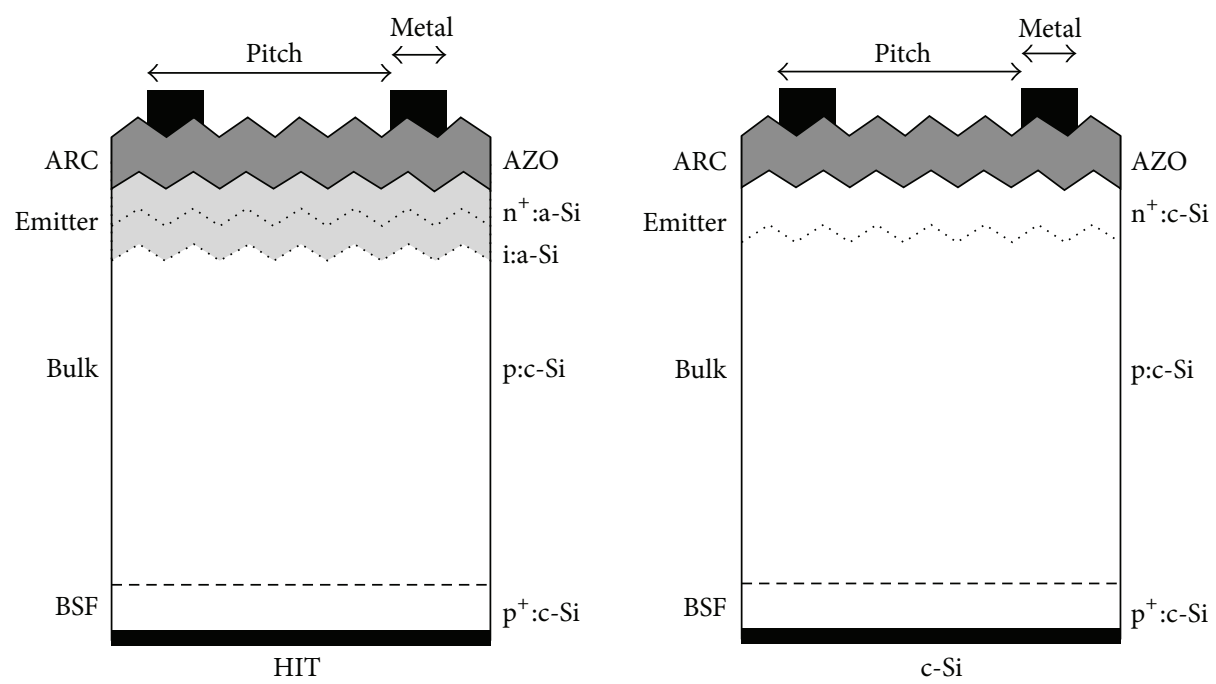

FIGURE 1: Schematic cross section of HIT and crystalline solar cell.

\section{Experimental Details}

The HIT structure is presented in Figure 1. Starting from a p-type CZ wafer, by a HF etching process a front random pyramids texturing is built. A highly doped p-type layer is deposited on the back surface, which is crystallized by a thermal process, forming the back surface field (BSF) layer. The intrinsic and the n-type amorphous layers are deposited by inductively coupled plasma chemical vapour deposition (ICPCVD) on the top surface of the wafer. The aluminum doped zinc oxide (AZO) is used as antireflective coating (ARC) layer and is grown by sputtering. To finalize the structure, the back metallization covers the entire device and is a $\mathrm{Ti} / \mathrm{Pt} / \mathrm{Au}$ multilayer; the top metal is made by screen printing of a silver paste. A double HIT structure was not realized, since the amorphous BSF does not add enhancement on a p-type HIT solar cell [7, 8]. For comparison purpose, we realized the crystalline structure shown in Figure 1. The device parameters of the HIT and the reference structures are reported in Table 1 . The key difference between the two structures is the emitter region, which is crystallized by a thermal process in the case of the crystalline structure.

The electrical simulation setup uses a drift-diffusion model with Fermi statistics, with the Schenk bandgap narrowing model [9] and the Slotboom model for free mobility carrier degradation [10]. The Auger and Radiative recombination has been added as far as the SRH recombination for both bulk and surfaces. For the crystalline solar cell, the surface recombination velocity of $\mathrm{c}-\mathrm{Si} / \mathrm{AZO}$ interface uses the SRH surface recombination model, tuned with literature results [11]; the doping level for both emitter and BSF layers is tuned with spreading resistance measurements on our devices. The HIT solar cell is made by replacing the emitter with the $\mathrm{i} / \mathrm{n}$ a-Si:H layers. The HIT physical model requires adding the thermionic current and the surface recombination at the amorphous-crystalline interface $[12,13]$. The amorphous silicon density of states (DOS) is modeled by three Gaussian
TABLE 1: Measurements of electrical and geometrical parameters for HIT and c-Si structures.

\begin{tabular}{lccc}
\hline & Unit & HIT & $\mathrm{c}-\mathrm{Si}$ \\
\hline Sheet resistance & $\Omega / \mathrm{sq}$ & 14 & 7.78 \\
AZO thickness & $\mathrm{nm}$ & 91 & 88 \\
Emitter thickness & $\mathrm{nm}$ & - & 50 \\
Emitter doping & $\mathrm{cm}^{-3}$ & - & $1 \times 10^{20}$ \\
n-type a-Si:H thickness & $\mathrm{nm}$ & 10 & - \\
n-type a-Si:H doping & $\mathrm{cm}^{-3}$ & $1 \times 10^{18}$ & - \\
i-type a-Si:H thickness & $\mathrm{nm}$ & 5 & - \\
Emitter/AZO SRV & $\mathrm{cm} / \mathrm{s}$ & $8.7 \times 10^{4}$ & $2.1 \times 10^{4}$ \\
i/n a-Si SRV & $\mathrm{cm} / \mathrm{s}$ & - & $10^{2}$ \\
\hline \multicolumn{4}{c}{ Electrical measurements } \\
Voc & $\mathrm{V}$ & 0.563 & 0.552 \\
Isc & $\mathrm{mA} / \mathrm{cm}^{2}$ & 25.0 & 30.5 \\
FF & - & 0.527 & 0.579 \\
Efficiency & $\%$ & 7.4 & 9.7 \\
\hline
\end{tabular}

distributions, two for the conduction and valence band tails and one for the mid gap defect concentration [13]. The most relevant a-Si:H electrical parameters used in the simulations are reported in Table 2 . The optical simulation solves an extended version of the Transfer Matrix Method with diffused and direct light to take into account surface texturing [14, 15]. The coherent light follows the direct path, while the diffused ray follows a scattered function, the so-called angular distribution function [16]. The ratio between the scattered and direct ray is the haze parameter. In the simulation above, the haze parameter has been set to 0.73 and the haze profile follows a square cosine law. The values of refractive index and absorption coefficient for the materials used in the solar cell are consistent with literature data [17]. 

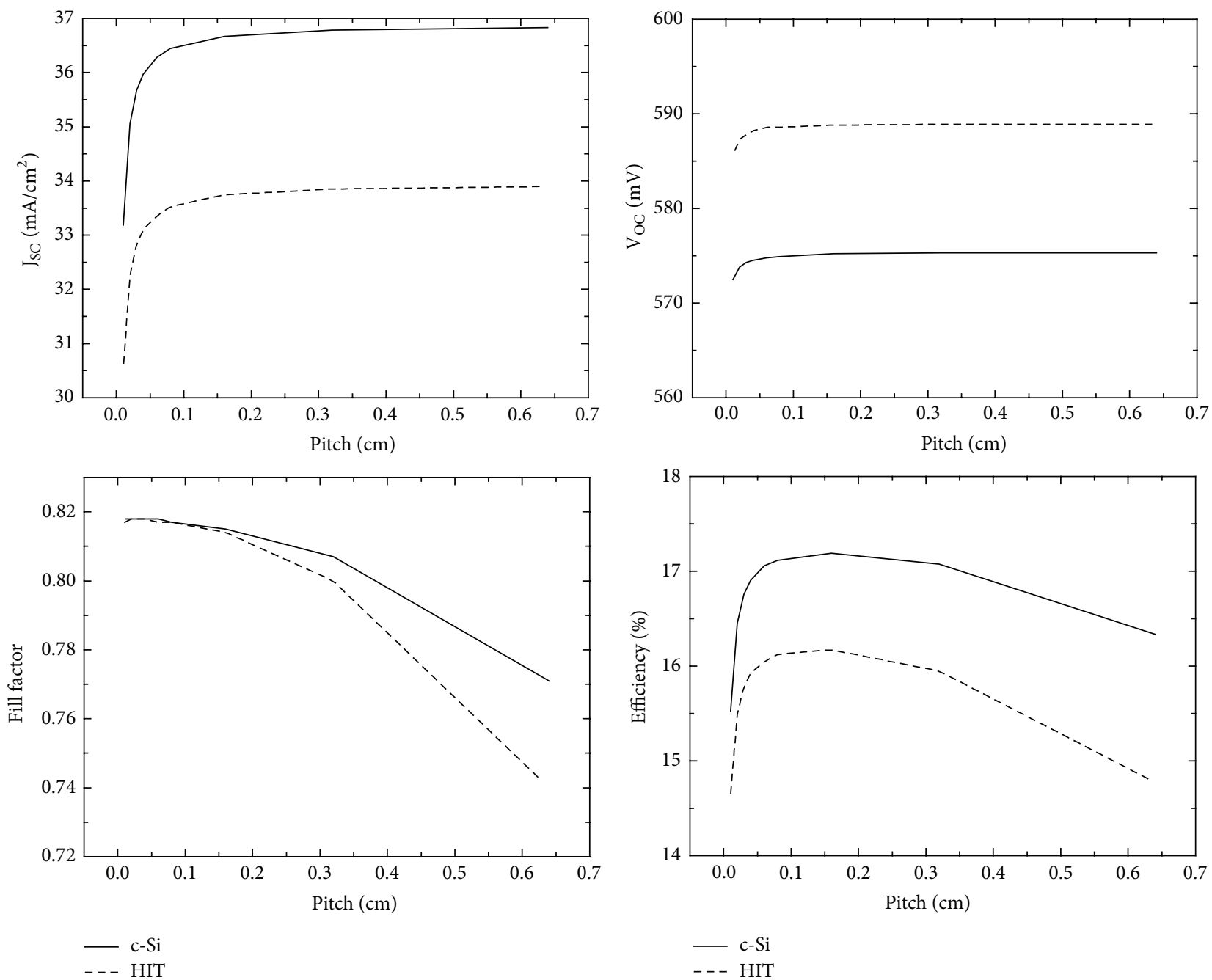

FIGURE 2: Simulated electrical parameters as a function of sun pitch length. The HIT shows a lower efficiency compared to the crystalline silicon structure.

\section{Results and Discussion}

Figure 2 shows the main electrical parameters of HIT and crystalline (subsequently c-Si) solar cells as a function of pitch. According to literature, the open circuit voltage of the HIT cell is greater than $\mathrm{c}-\mathrm{Si}$ [2]; on the other hand, the short circuit current and the fill factor are lower. This translates into a lower efficiency value of the HIT compared to $\mathrm{c}-\mathrm{Si}$, and the difference increases as the pitch increases. Figure 3 shows the optimized pitch distance that reaches the highest efficiency; this value reaches a trade-off between the shadowing losses and the fill factor that show opposite trends as a function of pitch length. Increasing the sun concentration, the pitch distance decreases faster in the cSi solar cell compared to HIT, thus increasing the efficiency of HIT compared to $\mathrm{c}$-Si. In order to understand the fill factor loss we analyze simulation results for both HIT and cSi structures at maximum power peak; results are shown in Figure 4, where the black lines are the current path and the color is the current density. It is worth noting that the current flows vertically inside the bulk, while it goes in direction of the contact in both the emitter and the AZO regions. The current direction into the emitter causes an increase of the density current near to the contact, thus increasing the electrostatic potential loss inside the emitter. This effect depends on the pitch width and the emitter resistivity. In order to gain insight on the lateral loss effect, Figure 5 compares the electrostatic potential along the c-Si/a-Si heterointerface for the HIT structure and the electrostatic potential at the $p-n$ junction for the c-Si structure. Moving away from the contact, the potential decreases due to the emitter and $\mathrm{AZO}$ resistivity. The potential loss is highly close to the contact due to the higher current density and is higher in the HIT compared to the reference one, due to the higher resistivity of a-Si compared to $\mathrm{c}-\mathrm{Si}$. The electrostatic potential at the interface causes an increase in the dark current that decreases the photogenerated current. This effect depends on the operation condition. At short circuit current condition, the dark current is low with respect to the photogenerated current, so the effect can be neglected. By increasing the voltage, the diode current 
TABLE 2: Main physical parameters for the a-Si material for simulation.

\begin{tabular}{|c|c|c|}
\hline Name & Unit & Value \\
\hline Electron affinity & $\mathrm{eV}$ & 3.9 \\
\hline Bandgap & $\mathrm{eV}$ & 1.74 \\
\hline Electron mobility & $\mathrm{cm}^{2} \mathrm{~V}^{-1} \mathrm{~s}^{-1}$ & 20 \\
\hline Hole mobility & $\mathrm{cm}^{2} \mathrm{~V}^{-1} \mathrm{~s}^{-1}$ & 2 \\
\hline DOS in $\mathrm{CB}$ & $\mathrm{cm}^{-3}$ & $2.5 \times 10^{20}$ \\
\hline DOS in VB & $\mathrm{cm}^{-3}$ & $2.5 \times 10^{20}$ \\
\hline \multicolumn{3}{|c|}{ Conduction band tail } \\
\hline Traps concentration & $\mathrm{cm}^{-3}$ & $1 \times 10^{18}$ \\
\hline Standard deviation & - & 0.08 \\
\hline Capture cross section for $\mathrm{e}^{-}$ & $\mathrm{cm}^{-2}$ & $1 \times 10^{-16}$ \\
\hline \multicolumn{3}{|c|}{ Valence band tail } \\
\hline Traps concentration & $\mathrm{cm}^{-3}$ & $1 \times 10^{18}$ \\
\hline Standard deviation & - & 0.08 \\
\hline Capture cross section for $\mathrm{e}^{-}$ & $\mathrm{cm}^{-2}$ & $1 \times 10^{-19}$ \\
\hline \multicolumn{3}{|c|}{ Mid gap } \\
\hline Traps concentration & $\mathrm{cm}^{-3}$ & $1 \times 10^{16}$ \\
\hline Standard deviation & - & 0.15 \\
\hline Capture cross section & $\mathrm{cm}^{-2}$ & $1 \times 10^{-16}$ \\
\hline
\end{tabular}

becomes relevant with respect to the photogenerated current, and the effect cannot be neglected anymore. At open circuit voltage, the diode dark current is equal to the photogenerated current, since the dark current depends on the lateral effect; there is an open circuit voltage reduction. This phenomenon is present in both HIT and crystalline devices. As can be seen from Figure 5, the potential variation in the HIT structure is higher than the crystalline solar cell because of the higher emitter resistivity; the higher potential variation produces a decrease in the fill factor and in the open circuit voltage. In order to reduce this effect we need to shrink the pitch, thus causing a higher shadowing that decreases efficiency. The optimum value between lateral losses and shadowing is shown in Figure 3. Because of the previous effect, the HIT solar cell needs a smaller pitch than the c-Si, but with increasing sun concentration this effect tends to decrease, since the c-Si solar cell pitch decreases faster than the HIT and when the two pitch values are the same the HIT efficiency becomes greater than the $\mathrm{c}$-Si one.

Figure 6 shows the reflectivity of the devices for both simulations and measurements. As can be seen, the HIT structure shows a higher reflectivity from $300 \mathrm{~nm}$ to $600 \mathrm{~nm}$ with respect to the c-Si structure. This reflectivity increase translates into a lower energy absorbed by the solar cell and less energy. Figure 7 shows the difference of spectral power density absorbed by the HIT and c-Si solar cell with respect to the AM1.5G spectral density; this is an optical analysis derived from the overall reflectivity and transmittance; we cannot notice electrical issues and cannot determine which layer adsorbs the light. The optical stack of HIT structure differs from the $\mathrm{c}$-Si structure by the addiction

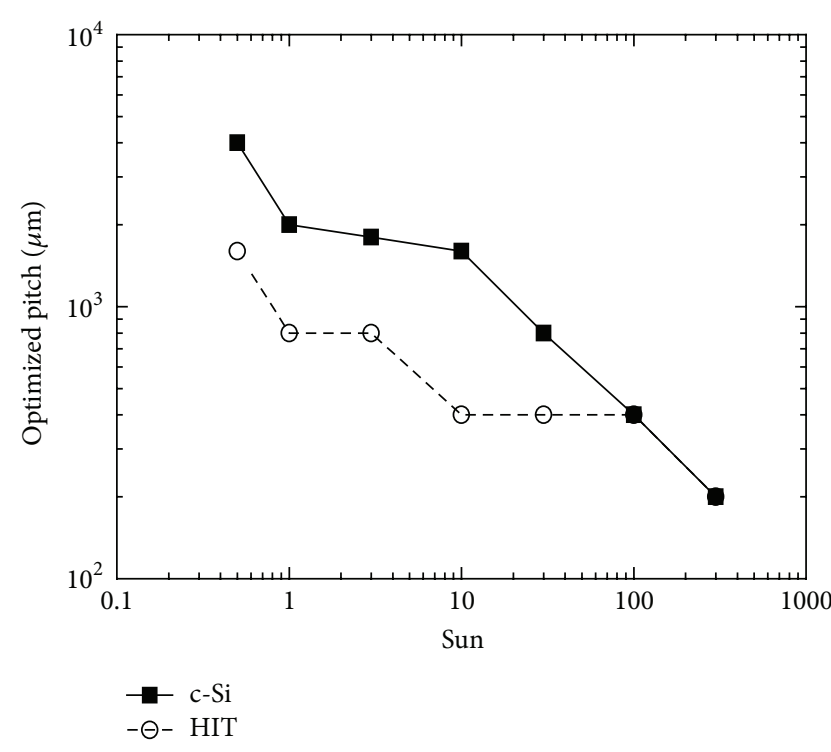

FIGURE 3: Optimized pitch for planar solar cell with metal line width equal to $100 \mu \mathrm{m}$ in HIT and c-Si solar cell. Lower values are observed for HIT, unless at very high sun concentration.

of the two a-Si:H layers, the n-doped and intrinsic layers (stack successfully called a-Si:H) in between the silicon bulk and the AZO layer. From literature we know that a good antireflective layer in between two materials must obey some rules; in particular, the thickness of the layer must ensure the destructive interference of the reflected wave and the refractive index must be as close as possible to the square root of the product of the refractive indices of the two materials. If the layers are more than one, we must use the same rule for the two neighbor materials. Figure 8 shows the refractive index of the c-Si, a-Si:H, and AZO material compared with the optimum refractive index for the case of 1 layer in between $\mathrm{c}-\mathrm{Si}$ and the air and the case of 2 layers (like HIT structure). As can be seen, the AZO is a good material to use as single inner layer for c-Si solar cell; this ensures a low reflectivity in c-Si solar cell. The a-Si:H shows a refractive index similar to the $\mathrm{c}$-Si for wavelength higher than $550 \mathrm{~nm}$; then the reflectivity in this wavelength range should be approximated to the c-Si solar cell. For smaller frequencies, the a-Si:H and $\mathrm{c}$-Si refractive indices are no more similar; this implies that the optical behavior must follow the model with 2 layers in between the silicon and the air. Under this range, the AZO is still a good material, but the a-Si:H is close enough to the optimum level for wavelength smaller than $400 \mathrm{~nm}$; before this value the worst index matching does not ensure a low reflectivity. This analysis is in good agreement with the optical measurements shown in Figure 6. The integral of the reflectivity value is used as a figure of merit for the system and Figure 9 shows this integral as a function of the a-Si:H layer thickness compared to the structure with no a-Si:H layer. The inset figure shows that the AZO reaches a minimum of reflectivity when its thickness is $91 \mathrm{~nm}$ and this value is not dependent on the a-Si:H thickness. The a-Si:H thickness affects the reflectance and there is a maximum of reflectance 

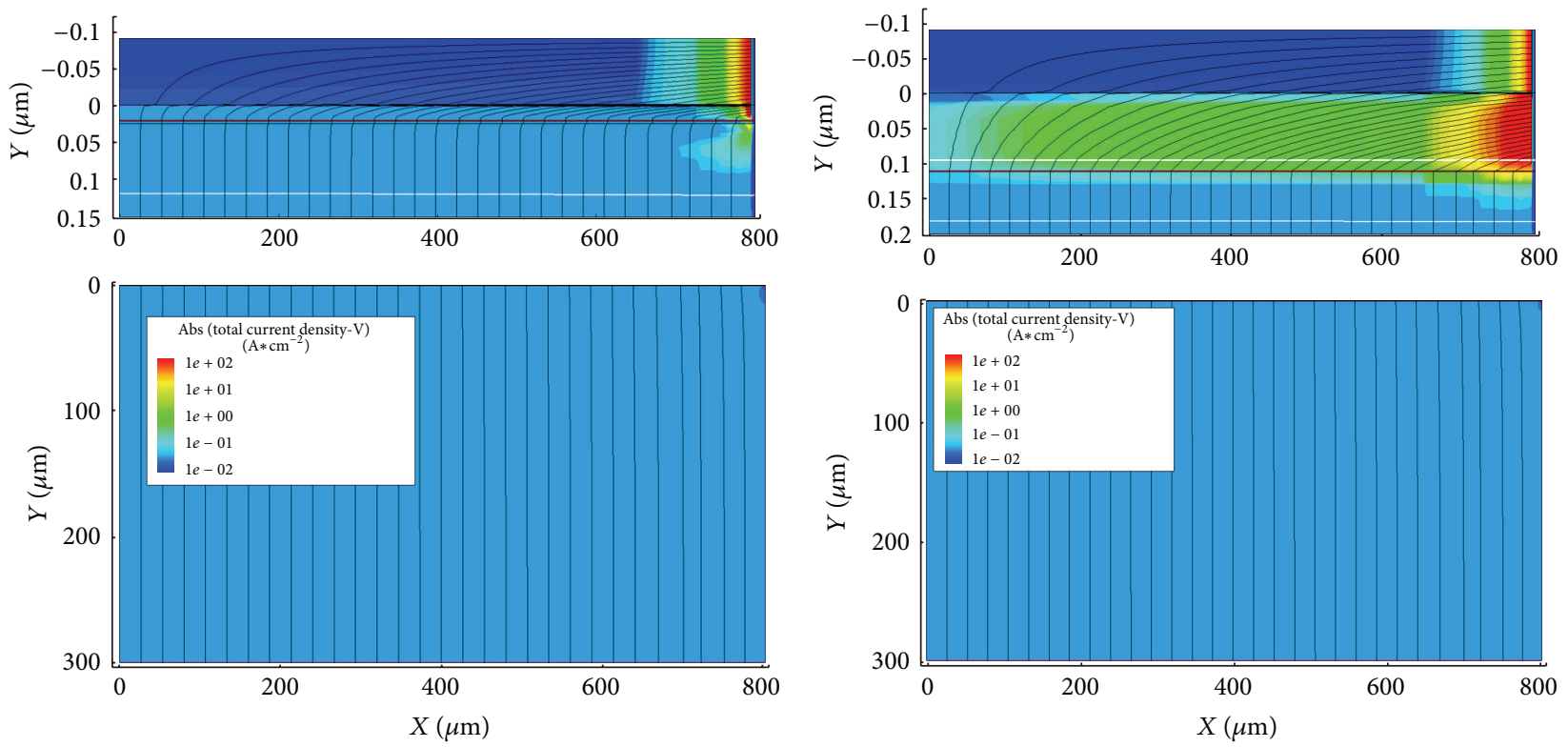

(a)

(b)

FIGURE 4: Cross section of HIT (a) and reference (b) solar cell for AM 1.5G illumination spectrum, at the voltage of maximum power peak, the top image is a zoom on the emitter region. Lines are for the current and colors for current density. The emitter contact is on the right.

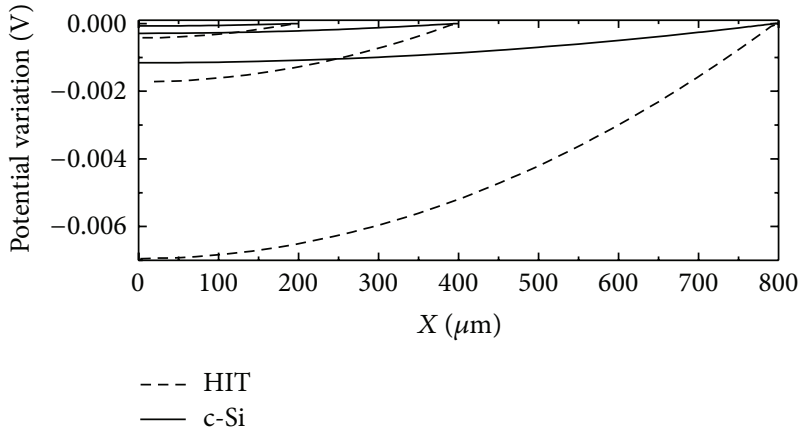

(a)

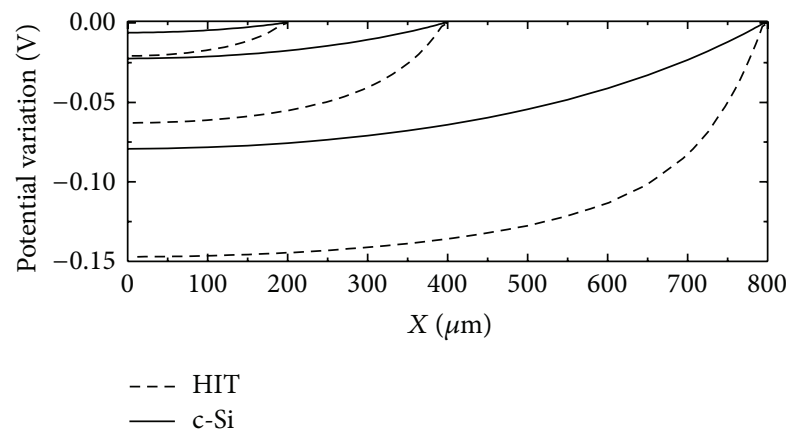

(b)

FIGURE 5: Horizontal cutline of the electrostatic potential profile at amorphous/crystalline heterojunction in HIT and at junction level for reference solar cell. Both cells are at maximum power condition. (a) For sun $=1$ and (b) for sun $=100$. The metal width is $10 \mu \mathrm{m}$ and the pitch is 400,800 , and $1600 \mu \mathrm{m}$.

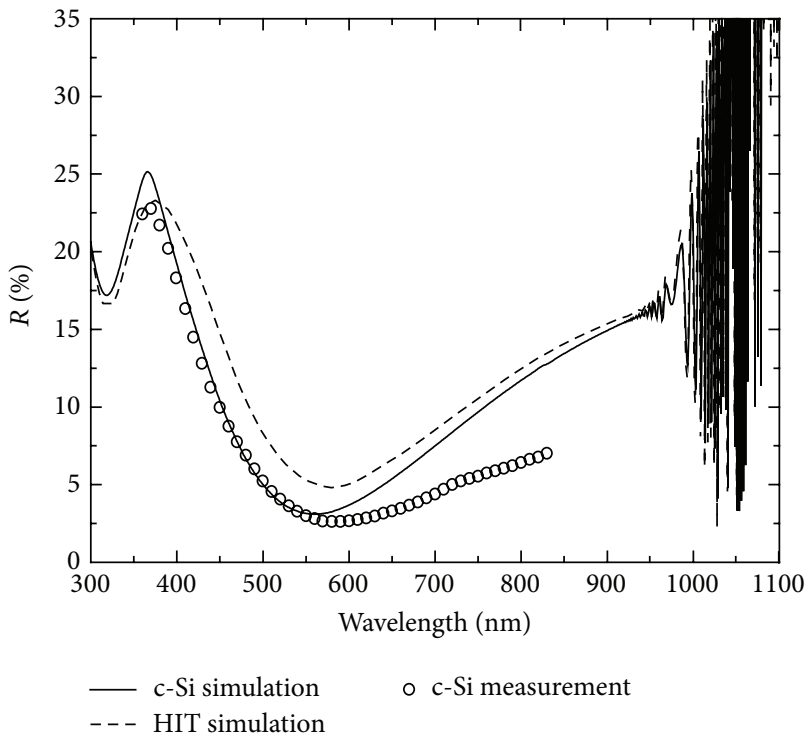

FIgURE 6: Measured and simulated reflectivity of c-Si solar cell and HIT solar cell with AZO as ARC. HIT solar cell exhibits a lower (higher) reflectivity at lower (higher) wavelengths with respect to the c-Si solar cell. The minimum reflectivity value for the HIT solar cell occurs at higher wavelength than the c-Si solar cell.

at $20 \mathrm{~nm}$. This result tells us to use a very thin a-Si:H layer or a greater one. But using a thick layer implies a bigger series resistance and a layer thinner than $5 \mathrm{~nm}$ can be a problem for quantum effects [18]. 


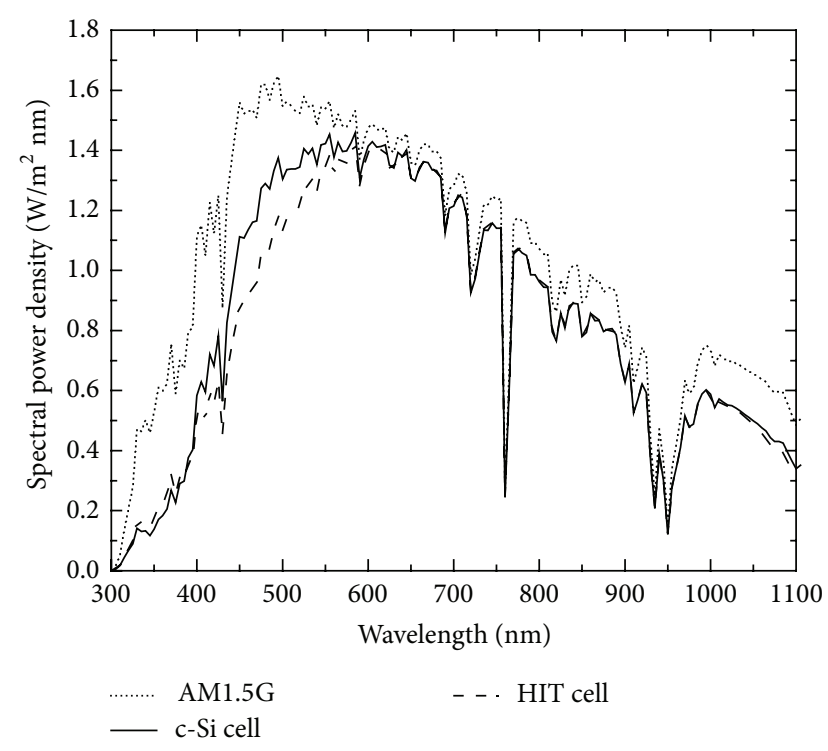

FIgURE 7: Spectral power density transmitted to the solar cell compared to the solar spectrum AM1.5G. This measurement shows a difference between the crystalline and HIT cell from $400 \mathrm{~nm}$ to $600 \mathrm{~nm}$, related to the higher reflectivity.

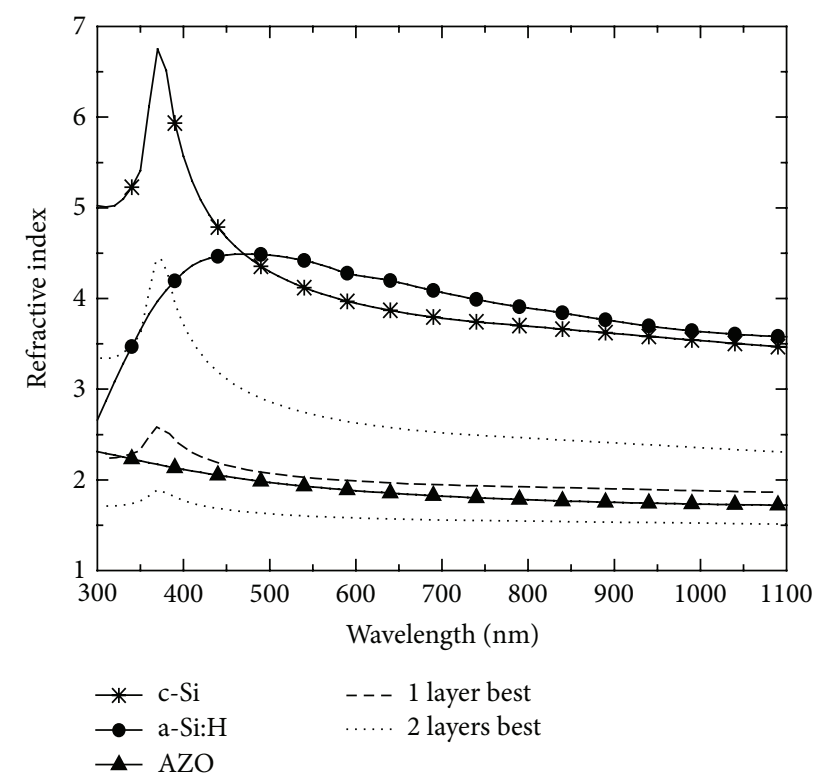

FIGURE 8: Refractive index of c-Si, a-Si:H, and AZO (by ellipsometry measures) compared to the ideal refractive index of an antireflective coating composed of 1 layer and 2 layers.

\section{Conclusions}

In this paper we compared the HIT solar cell with a c-Si solar cell to identify the main problems of the HIT technology. We made measurements and simulation and by comparing the optimized structure for both technologies we noticed two losses differences into HIT. A lower fill factor and a higher reflectivity for the HIT solar cell. The fill factor decrease is due to a higher potential loss along the $\mathrm{p}-\mathrm{n}$ junction that causes

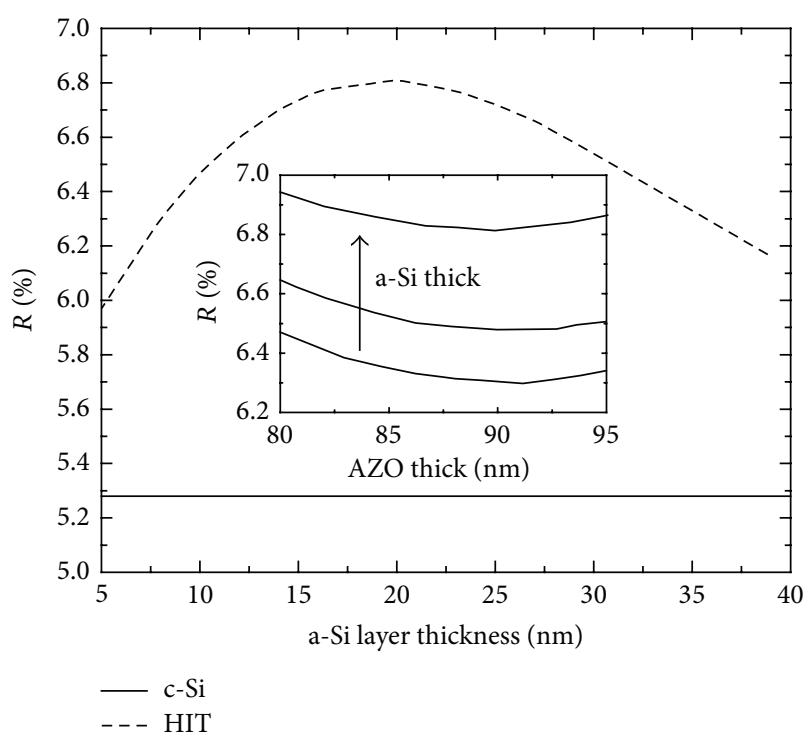

FIGURE 9: Total reflectivity of HIT as a function of a-Si:H layer thickness compared to $\mathrm{c}$-Si. Inset figure for total reflectivity as a function of AZO thickness for a-Si:H layer thickness of 8, 10, and $20 \mathrm{~nm}$.

a higher diode current. To prevent this we need to shrink the pitch, causing a higher shadowing. The lower short circuit current is caused by higher reflection losses into HIT. This is caused by the worst optical coupling between the amorphous silicon and the antireflective coating in the wavelength range from $400 \mathrm{~nm}$ to $600 \mathrm{~nm}$; we cannot reduce this effect since the reduction is related to optical properties of the amorphous layer; to reduce the reflectivity we must shrink the a-Si layer, but the thickness cannot be smaller than the value in use to prevent quantum effects.

\section{Conflict of Interests}

The authors certify that they have no affiliations with or involvement in any organization or entity with any financial interest (such as honoraria; educational grants; participation in speakers' bureaus; membership, employment, consultancies, stock ownership, or other equity interests; and expert testimony or patent-licensing arrangements) or nonfinancial interest (such as personal or professional relationships, affiliations, knowledge, or beliefs) in the subject matter or materials discussed in this paper.

\section{References}

[1] M. Tanaka, M. Taguchi, T. Matsuyama et al., "Development of new a-Si/c-Si heterojunction solar cells: ACJ-HIT (Artificially Constructed Junction-Heterojunction with Intrinsic Thin-layer)," Japanese Journal of Applied Physics, vol. 31, no. 11, pp. 3518-3522, 1992.

[2] M. Nath, P. Chatterjee, J. Damon-Lacoste, and P. Roca i Cabarrocas, "Criteria for improved open-circuit voltage in a$\mathrm{Si}: H(N) / c-S i(P)$ front heterojunction with intrinsic thin layer 
solar cells," Journal of Applied Physics, vol. 103, no. 3, Article ID 034506, 2008.

[3] M. A. Green, K. Emery, Y. Hishikawa, W. Warta, and E. D. Dunlop, "Solar cell efficiency tables (version 39)," Progress in Photovoltaics: Research and Applications, vol. 20, no. 1, pp. 1220, 2012.

[4] S. Tohoda, D. Fujishima, A. Yano et al., "Future directions for higher-efficiency HIT solar cells using a Thin Silicon Wafer," Journal of Non-Crystalline Solids, vol. 358, no. 17, pp. 2219-2222, 2012.

[5] T. Mishima, M. Taguchi, H. Sakata, and E. Maruyama, "Development status of high-efficiency HIT solar cells," Solar Energy Materials \& Solar Cells, vol. 95, no. 1, pp. 18-21, 2011.

[6] SYNOPSYS, Sentaurus Device User Manual, chapter 21, 2013.

[7] L. Zhao, C. L. Zhou, H. L. Li, H. W. Diao, and W. J. Wang, "Design optimization of bifacial HIT solar cells on p-type silicon substrates by simulation," Solar Energy Materials and Solar Cells, vol. 92, no. 6, pp. 673-681, 2008.

[8] A. Datta and P. Chatterjee, "Computer modeling of heterojunction with intrinsic thin layer 'HIT' solar cells: sensitivity issues and insights gained," in Solar Cells-Thin-Film Technologies, L. A. Kosyachenko, Ed., InTech, 2011.

[9] A. Schenk, "Finite-temperature full random-phase approximation model of band gap narrowing for silicon device simulation," Journal of Applied Physics, vol. 84, no. 7, pp. 3684-3695, 1998.

[10] D. B. M. Klaassen, "A unified mobility model for device simulation-I. Model equations and concentration dependence," Solid-State Electronics, vol. 35, no. 7, pp. 953-959, 1992.

[11] M. J. Kerr, J. Schmidt, A. Cuevas, and J. H. Bultman, "Surface recombination velocity of phosphorus-diffused silicon solar cell emitters passivated with plasma enhanced chemical vapor deposited silicon nitride and thermal silicon oxide," Journal of Applied Physics, vol. 89, no. 7, pp. 3821-3826, 2001.

[12] A. Kanevce and W. K. Metzger, "The role of amorphous silicon and tunneling in heterojunction with intrinsic thin layer (HIT) solar cells," Journal of Applied Physics, vol. 105, no. 9, Article ID 094507, 2009.

[13] K. Horio and H. Yanai, "Numerical modeling of heterojunctions including the thermionic emission mechanism at the heterojunction interface," IEEE Transactions on Electron Devices, vol. 37, no. 4, pp. 1093-1098, 1990.

[14] A. Gerrard and J. M. Burch, Introduction to Matrix Methods in Optics, Dover Publications, 2012.

[15] J. Krč, F. Smole, and M. Topič, "Analysis of light scattering in amorphous $\mathrm{Si}: \mathrm{H}$ solar cells by a one-dimensional semicoherent optical model," Progress in Photovoltaics: Research and Applications, vol. 11, no. 1, pp. 15-26, 2003.

[16] P. Beckmann and A. Spizzichino, The Scattering of Electromagnetic Waves from Rough Surfaces, Artech House, Norwood, Mass, USA, 1987.

[17] E. D. Palik, Handbook of Optical Constants of Solids, Academic Press, Boston, Mass, USA, 1985.

[18] A. Muoz, N. Chetty, and R. M. Martin, "Modification of heterojunction band offsets by thin layers at interfaces: role of the interface dipole," Physical Review B, vol. 41, no. 5, pp. 29762981, 1990. 

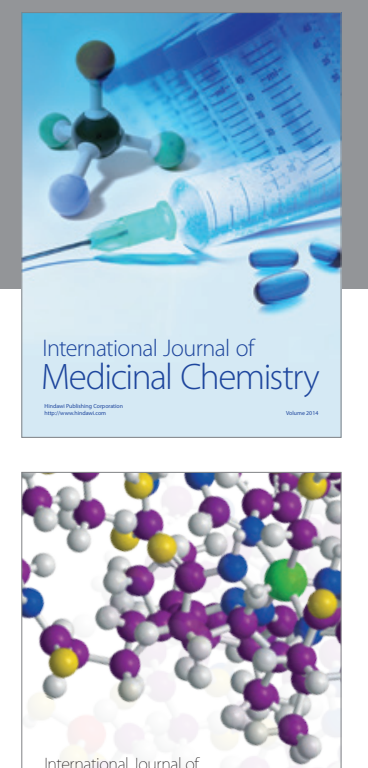

\section{Carbohydrate} Chemistry

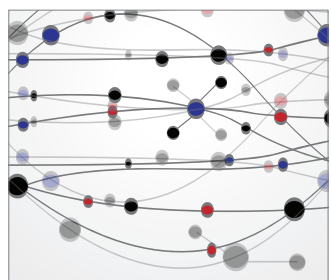

The Scientific World Journal
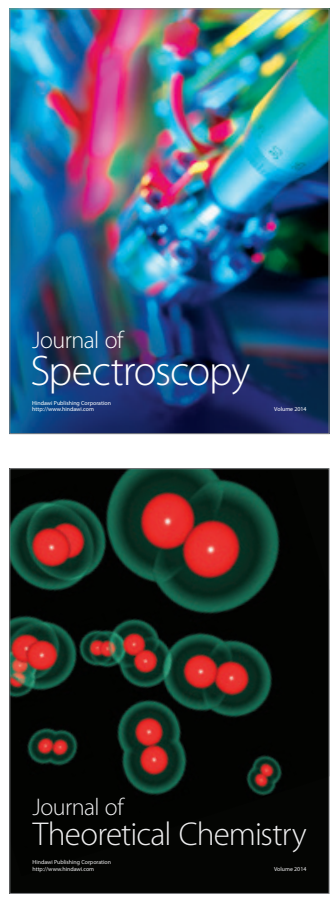
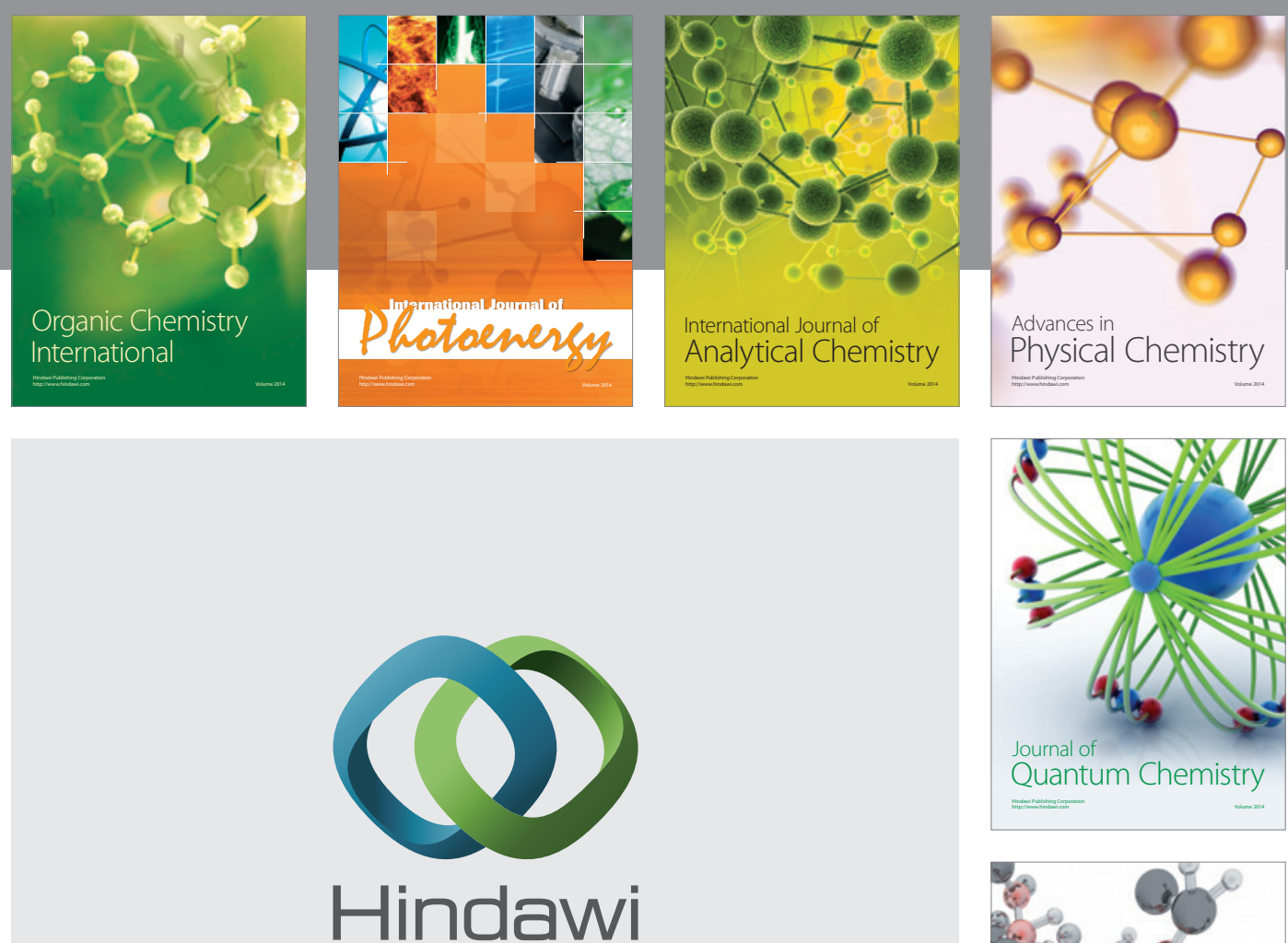

Submit your manuscripts at

http://www.hindawi.com

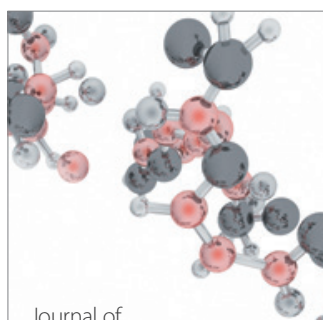

Analytical Methods

in Chemistry

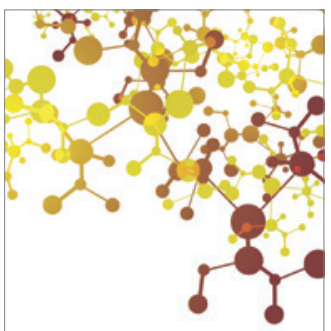

Journal of

Applied Chemistry

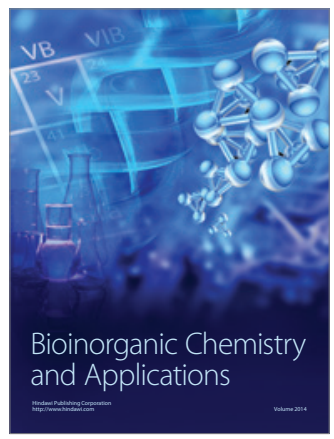

Inorganic Chemistry
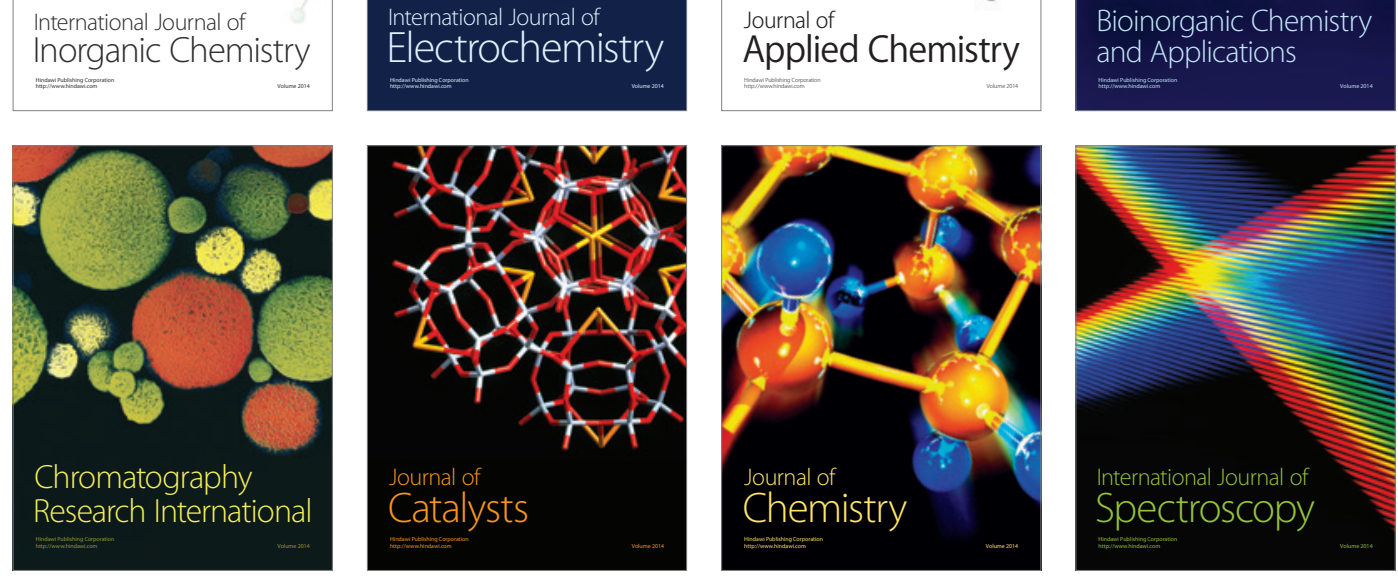